\title{
O EU DO FUTURO: CONTRIBUIÇÕES DO PSICODRAMA INTERNO ON-LINE
}

\author{
Carolina Ferreira Cortes Novaes ${ }^{1, *}$ (D), Gabriela Pereira Vidal² (D)
}

\section{RESUMO}

A pandemia de Covid-19, entre suas muitas consequências, trouxe aumento nas demandas relacionadas à saúde mental. Assim, o objetivo deste relato foi evidenciar como o psicodrama interno on-line contribui para abordar as angústias e ansiedades que surgiram com a pandemia da Covid-19. Trata-se de um estudo de caso, de um paciente em psicoterapia psicodramática bipessoal on-line. Conclui-se que a realização simbólica deste futuro na realidade suplementar auxiliou na preparação do paciente diante das incertezas do futuro pós-pandemia.

PALAVRAS-CHAVE: Psicodrama; Coronavírus; Psicoterapia.

\section{THE SELF OF THE FUTURE: CONTRIBUTIONS FROM ONLINE INTERNAL PSYCHODRAMA}

\begin{abstract}
As a result of the Covid-19 pandemic, among its many consequences, the number of lawsuits related to mental health has increased. In addition, the purpose of this story was to show how internal online psychodrama contributed to dealing with the anxieties and anxieties that will arise with the Covid-19 pandemic. This is a case study, about a patient undergoing online bipersonal psychodramatic psychotherapy. It was concluded that the symbolic realization of that future will complement the help in preparing the patient in the face of the uncertainties of the post-pandemic future.
\end{abstract}

KEYWORDS: Psychodrama; Coronavirus; Psychotherapy.

\section{EL YO DEL FUTURO: CONTRIBUCIONES DEL PSICODRAMA INTERNO EN LÍNEA}

\section{RESUMEN}

Como consecuencia de la pandemia de Covid-19, entre sus múltiples consecuencias, ha aumentado el número de demandas relacionadas con la salud mental. Además, el propósito de esta historia fue mostrar cómo el psicodrama interno on-line contribuyó a lidiar con las ansiedades y ansiedades que surgirán con la pandemia de Covid-19. Este es un estudio de caso sobre un paciente que se somete a psicoterapia psicodramática bipersonal on-line. Se concluyó que la realización simbólica de ese futuro complementará la ayuda en la preparación del paciente frente a las incertidumbres del futuro pospandémico.

PALABRAS-CLAVE: Psicodrama; Coronavirus; Psicoterapia.

\footnotetext{
1.Associação Brasiliense de Psicodrama - Brasília (DF), Brasil.
}

2.Viver Mais Psicologia - Tubarão (SC), Brasil.

*Autora correspondente: carolinanovaes2010@gmail.com

Editora de seção: Amanda Castro

Recebido: 22 Mar 2021 | Aceito: 06 Abr 2021 


\section{INTRODUÇÃO}

Com a chegada da pandemia da Covid-19, a saúde mental ganhou destaque na perspectiva de cuidados pessoais da população. Assim, a busca por psicoterapia cresceu massivamente dentro do espaço profissional dos psicodramatistas. Em virtude das diretrizes oficiais da Organização Mundial da Saúde (2020) de distanciamento social para desacelerar a propagação do vírus, foi necessária a transposição do setting psicoterapêutico tradicional do psicodrama bipessoal para o ambiente on-line. Este movimento vinha acontecendo de maneira muito tímida, graças à publicação de resoluções do Conselho Federal de Psicologia, a exemplo da Resolução CFP n. 11 (2018), mas chegaram à realidade da psicologia clínica com maior intensidade com o agravamento da pandemia em 2020.

Psicodramatistas contemporâneos vêm compartilhando e processando atuações dentro do setting de telepsicoterapia, demonstrando uma alternativa não só possível, como muito vantajosa. Além disso, há compartilhamento entre os psicodramatistas clínicos que já adaptam outras técnicas utilizadas no psicodrama bipessoal, como é o caso de Guimarães (2020) e Vidal e Cardoso (2020).

Diante da pandemia da Covid-19, muitas temáticas apareceram no palco dos pacientes. Adoecimento fisiológico e mental, isolamento afetivo, luto, dentre outros temas, apresentaram-se dentro do contexto psicoterapêutico com maior frequência. São possíveis traumas relacionados à perda ou à mudança de papéis que o indivíduo tinha, até mesmo sensações de incerteza acerca do futuro, gerando angústia, desespero, ansiedades ou pavor, gerados por vários fatores, como, por exemplo, o medo da contaminação (Crepaldi et al., 2020; Do Bú et al., 2020).

Diante disso, faz-se importante o uso da realidade suplementar. Perazzo (2010, p. 109) destaca:"a realidade suplementar como terreno de atuação da criatividade e expressão viva da imaginação e da fantasia, na cena psicodramática, torna-se concretude por meio da construção e da interação de personagens”. A realidade suplementar, neste estudo de caso, apresenta-se através da técnica de projeção para o futuro, na qual o cliente representa, na ação dramática, aquilo que crê para seu futuro (Z. T. Moreno, 1975). Assim, através da realização simbólica ${ }^{1}$, tem a possibilidade de transformar seus sucessos simbólicos em reais no palco psicodramático (Moreno, 1974).

Para isso, utilizou-se do psicodrama interno, que Fonseca (2010) descreve como uma forma de ampliação da consciência corporal e de diminuição dos pensamentos, através da qual é possível visualizar imagens de maneira interna, uma dramatização simbólica em que se imagina a realização da cena, dos diálogos, dentre outros aspectos da dramatização. Assim, o objetivo deste relato foi evidenciar como o psicodrama interno no contexto on-line contribui para abordar as angústias e ansiedades que surgiram com a pandemia da Covid-19.

\section{MÉTODO}

Trata-se de um estudo de caso, uma descrição detalhada da compreensão e das intervenções realizadas, muito utilizada nas ciências humanas e de saúde (Brito, 2006), com base no método psicodramático. Baseia-se no recorte de uma sessão com um paciente, descrito aqui pelo nome fictício German, que está em psicoterapia psicodramática on-line há sete meses com uma das autoras. As sessões eram realizadas por videochamadas com duração de 50 minutos, na plataforma Zenklub.

As sessões psicodramáticas são divididas em: aquecimento, que prepara o protagonista para a ação; dramatização, a ação propriamente dita; e compartilhamento, no qual psicoterapeuta e paciente compartilham sensações, sentimentos e pensamentos, visando ao acolhimento da demanda trazida. Foram utilizados os instrumentos do psicodrama: diretor, que conduz a ação; protagonista, aquele no qual está centrada a ação dramática; ego-auxiliar (neste caso, o próprio diretor faz a função de ego); cenário ou palco, local onde ocorre a ação dramática, no caso do psicodrama on-line, uma junção das telas de diretor e protagonista; e plateia, elemento ausente no psicodrama bipessoal (Cukier, 1992). Além disso, utilizou-se da técnica do psicodrama interno, que conta com três etapas: fase inicial de relaxamento, fase calcada no iniciador emocional e, por último, a dramatização dessas personagens (Cukier, 1992). 
De acordo com Brito (2006, p. 38), baseando-se na teoria moreniana, os psicodramatistas são pesquisadores qualitativos, "sempre fazendo perguntas e encontrando meios para respondê-las". Assim, a análise ocorreu com base nos preceitos epistemológicos e teóricos morenianos e pós-morenianos, utilizando-se dos conceitos de instrumentos, etapas e técnicas da socionomia.

\section{ESTUDO DE CASO}

German, 28 anos, iniciou o processo psicoterapêutico durante a pandemia da Covid-19. Nunca havia feito terapia e apresentou um pouco de resistência no início. Durante o processo psicoterapêutico, buscou-se sempre um caminho de maior autoconhecimento sobre sua vida. Dentre suas principais demandas, havia uma necessidade em pensar sua vida como uma linha do tempo. Com uma história de vida baseada em uma linearidade lógica, a pandemia trouxe para German um novo "enredo pessoal": a partir de agora, parecia muito difícil fazer planos e programações pessoais e profissionais para sua vida no futuro, representando um possível contexto traumático, inclusive, pois interrompeu drasticamente muitos de seus planos (Castro et al., 2020).

Assim, de acordo com Khouri (2020), o trabalho com traumas pode ser realizado utilizando o psicodrama interno, de maneira a favorecer o reprocessamento em níveis cognitivo, emocional e sensório-motor. Diante disso, a diretora buscou uma estratégia ligada à exploração de papéis psicodramáticos internos e ao exercício de uma visão de futuro que não dependesse de uma linearidade, por meio do psicodrama interno dirigido no psicodrama on-line.

\section{Aquecimento inespecífico: A definição do tema}

A atuação como psicodramatista é pautada no conceito moreniano de espontaneidade como a "disposição do sujeito de responder como requerido. É uma condição - um condicionamento - do sujeito; uma preparação para a livre ação" (J. L. Moreno, 1975, p. 162). Assim, para a diretora deste relato, estar mais preparada para conseguir atender à demanda dos pacientes é não ter um script predeterminado. Dessa forma, iniciou-se a sessão com uma pequena conversa sobre como German estava se sentindo em relação aos últimos encontros, nos quais o tema foi sua carreira e o que tinha planejado até o momento de pandemia. Essa conversa inicial já é um aquecimento (Cukier, 1992).

German relatava ter muita clareza quanto às conquistas que almejava durante a sua adolescência e o início da vida adulta. Porém, com a pandemia, percebeu certa dificuldade em imaginar seu enredo pessoal e profissional para o futuro. Essa incerteza e outras angústias vêm sendo relatadas em estudos que relacionam a pandemia e agravamentos em relação à saúde mental (Do Bú et al., 2020); sendo assim, buscou-se visualizar como seria seu futuro dentro de alguns anos, utilizando da realidade suplementar, descrita por Moreno et al. (2001, p. 45) como "uma técnica para completar e curar, para ter um efeito integrador sobre o ego, de forma que o protagonista se sinta melhor e consiga tocar para a frente a sua vida”. Realizou-se uma projeção do futuro, que permite ao indivíduo uma reflexão sobre fantasias e emoções do momento presente, além de possibilitar ao paciente a percepção de ser o criador do seu próprio futuro (Crelier, 1992).

\section{Aquecimento específico: Um relaxamento}

Para este exercício, a psicodramatista utilizou a técnica do psicodrama interno. Assim, pediu que o paciente diminuísse a luminosidade do local de psicoterapia e se deitasse de maneira confortável, mas de forma que ela ainda pudesse vê-lo, principalmente o rosto dele. A diretora ligou uma música de relaxamento no seu setting terapêutico e the pediu que confirmasse se ouvia bem. Diante da resposta afirmativa, iniciou um relaxamento com base em controle da respiração, focalizando articulações e algumas musculaturas que abrigam tensões emocionais (Miguel, 2015; Vieira et al., 2018).

O uso da música e do trabalho corporal se baseia no conceito de iniciadores, estímulos internos ou externos, voluntários ou não, para aquecimento do paciente (Almeida, 2020), divididos didaticamente em corporais, emocionais e ideativos (Bustos, 1985). Porém, de acordo com Perazzo (2010, p. 136), um tipo de iniciador não opera separado do outro, eles têm 
uma ligação íntima e operam juntos. De acordo com ele, "apenas o diretor percebe primeiro um deles ou toma a iniciativa de acionar primeiro um ou outro. Isso se dá em segundos”. Assim, quando a diretora estimula o corpo e a emoção, logo todos os tipos de iniciadores serão estimulados.

Como principal consigna, após o período de relaxamento, pediu para que o paciente conversasse com ela durante o psicodrama interno. Assim a diretora pôde acompanhá-lo nesse momento, facilitando o próprio aquecimento para tal (Vidal \& Cardoso, 2020). Depois disso, pediu para que imaginasse ambos, diretora e paciente, flutuando e se distanciando do momento atual. Assim como no psicodrama clássico, o papel do diretor continua importante dentro do palco do psicodrama interno, no qual este ocupa um lugar de análise do conteúdo interno, não podendo estar fora da cena, para garantir a qualidade da ação dramática (Moreno \& Enneis, 1984).

\section{Dramatização: Indo ao encontro do momento futuro}

Após o distanciamento solicitado, a diretora pediu que ele se imaginasse no futuro. Ele relatou ver dois Germans: um de 35 anos de idade e outro de 45. A diretora pediu que escolhesse um deles para visitarem, e ele escolheu visitar seu papel psicodramático de 45 anos. Encontrava-se morando em uma praia, casado com a atual namorada e pai de duas crianças. A diretora pediu que descrevesse a cena e que interagisse com os personagens da forma que tivesse vontade. Descreveu que foi convidado para entrar, deparou-se com uma mesa farta e foi convidado a se sentar. Observou como a relação conjugal, em seu psicodrama interno, parecia muito saudável e feliz.

A descrição da sua relação afetiva para o caso é muito significativa, pois German sempre trouxe uma preocupação e um zelo com relação à qualidade dela, desde o início do relacionamento até os momentos futuros, em que sempre relatou o desejo, o planejamento e a execução de atividades que concretizavam o casamento. Além disso, a descrição também evidencia nível de aquecimento, já que "ao diretor cabe a ciência e a arte de proporcionar a dosagem certa de aquecimento que, por sua vez, garantirá a liberação da espontaneidade e iluminará o caminho desconhecido e sempre surpreendente da ação psicodramática" (Santos \& Conceição, 2014, p. 63).

Depois de o German atual ter se sentado à mesa e conversado amigavelmente com sua versão de 45 anos de idade, sua esposa e seus dois filhos, a diretora pediu que ele conversasse com seu papel psicodramático de 45 anos, no psicodrama interno. Então, German de 28 anos convidou o German de 45 anos para se sentar ao lado de fora da casa. Ambos começaram a fumar um cigarro e trocaram informações e percepções com relação à vida. O German de 28 perguntou como tinha sido a vida até aquele momento, quais tinham sido os principais desafios, sobre o trabalho e o relacionamento amoroso. Também perguntou se ele estava feliz e realizado e pediu uma dica para os momentos atuais. Essa conversa com o eu do futuro "permite visualizar expectativas, presságios, repetições do passado e mesmo entender algumas condutas no presente" (Cukier, 1992, p. 81). Além disso, no contexto pandêmico essa conversa permite ao cliente acolher suas angústias, além do fortalecimento dos papéis para que possa viver a ausência de controle da pandemia (Vidal \& Castro, 2020).

O German de 45 anos, no psicodrama interno, respondeu às perguntas com acolhimento e cuidado. Disse que o trabalho seguia bem, que havia chegado aonde ele gostaria, e ainda com os benefícios do home office, podendo viver de maneira mais tranquila e perto do mar, um desejo do German de 28 anos. Além disso, disse que seu casamento é algo muito satisfatório e que a vida a dois atinge suas expectativas atuais. Tem filhos lindos, pelos quais é apaixonado, e uma esposa muito companheira e que lhe faz muito feliz. Em relação à dica que German de 28 anos pediu, disse apenas que ele está no caminho certo e completou: "continue, respire, foque no trabalho e nas coisas que você valoriza, que as coisas vão seguir para o caminho que você espera". Essa conversa consigo mesmo permite que German se fortaleça quanto às relações e aos seus objetivos futuros e acalme a sensação de ansiedade gerada pelas incertezas da pandemia (Crepaldi et al., 2020).

Ao fim da conversa, a diretora pediu para que o German de 28 anos se despedisse do de 45 anos e dos demais personagens presentes. Em seguida, ela conduz para que voltem até a flutuação e se distanciem da cena. Nas orientações de direção, pediu que visualizasse o local onde estavam no momento presente e que se aproximasse, para que pudesse 
sair do estado de relaxamento físico. O retorno do relaxamento dá a oportunidade de o protagonista ressignificar o que ele viveu dentro do psicodrama interno - assim como em sonhos - , trazendo novas conexões com cenas que não foram diretamente trabalhadas. Como descrito por Moreno, "o efeito sobre o comportamento consciente do paciente prolonga-se bem além do choque inicial” (Moreno, 1974, p. 308).

\section{Compartilhamento: Reflexão no presente sobre a vivência no futuro}

Ao retornarem para o momento presente, fora do psicodrama interno, German compartilhou como a vivência parecia real. Além disso, trouxe a felicidade e realização em perceber que seus planos conscientes com relação ao que esperava do futuro estavam de fato se concretizando. Quanto a seu relacionamento, percebeu que estava construindo algo que realmente iria the trazer bons resultados no futuro, apesar de todos os desafios dos relacionamentos amorosos, principalmente em tempos de pandemia. Além disso, gostou da dica que recebeu de seu papel psicodramático de 45 anos: "continue no caminho, que as coisas vão sair conforme você está planejando".

Apesar de o momento ter alterado muito do seu planejamento feito nos últimos anos, German percebeu que, essencialmente, seus valores e crenças e a forma como se relaciona com os diferentes átomos da sua vida — familiar, afetivo e profissional - levaram-no para um lugar do qual se orgulha e quer fazer parte. Além disso, German pontuou como a experiência de um relaxamento e uma vivência interna foi surpreendente, reconhecendo como ele realmente "embarcou" nessa viagem para um lugar interno e relatando como as cenas que aconteciam dentro do seu espaço psicodramático interno pareciam-lhe reais. Isso deixa clara a contribuição do psicodrama interno no psicodrama on-line, visto que este é uma técnica possível de aplicação e que não precisou de adaptações em relação ao on-line, já que usa apenas da condução verbal do diretor. Essa abordagem foi totalmente inesperada e positiva, pois tirou-o do lugar da racionalidade e do pensamento linear. Este é um trabalho que foi realizado desde o seu início no processo psicoterapêutico.

\section{CONSIDERAÇÕES FINAIS}

Este relato apresenta uma das novas temáticas que apareceram dentro dos consultórios de psicodramatistas após o início da pandemia. Nele, foi possível observar a contribuição do psicodrama bipessoal on-line e, mais precisamente, da projeção para o futuro através do psicodrama interno em casos de incertezas em relação ao futuro e como a realização simbólica deste futuro na realidade suplementar auxiliou na preparação para estas. Destacamos a importância do maior compartilhamento de trabalhos desenvolvidos em diferentes temáticas no contexto pandêmico, para que apoiemos uns aos outros na construção de repertório para os novos desafios sociométricos presentes. Assim, sugerem-se novas pesquisas sobre o psicodrama on-line no contexto de pandemia.

Além disso, o treino da espontaneidade, principalmente no novo cenário, é extremamente importante para que as novas formas de fazer psicodrama mantenham a qualidade psicoterapêutica. Assim como trazido por Moreno (2016), é possível analisar casos de falta de escolha e solidão dentro de vários contextos sociais. Acreditamos que seja necessário revisar o tema dentro do contexto de pandemia, principalmente considerando o vínculo entre paciente e psicoterapeuta.

\section{CONTRIBUIÇÃO DAS AUTORAS}

Conceitualização: Novaes CFC, Vidal GP; Investigação: Novaes CFC; Escrita - Rascunho Original: Novaes CFC. Escrita \& Revisão: Vidal GP.

\section{DISPONIBILIDADE DE DADOS DE PESQUISA}

Todos os dados foram gerados ou apresentados neste estudo. 


\section{FINANCIAMENTO}

Não se aplica.

\section{AGRADECIMENTOS}

Não se aplica.

\section{REFERÊNCIAS}

Almeida, W. C. (2020). Técnicas dos iniciadores. In R. F. Monteiro (Org.), Técnicas fundamentais do psicodrama (pp. 32-44). Ágora.

Brito, V. (2006). Um convite à pesquisa: Epistemologia qualitativa e psicodrama. In A. M. Monteiro, D. Merengué, \& V. Brito, Pesquisa qualitativa e psicodrama (pp. 15-56). Ágora.

Bustos, D. (1985). Psicoterapia psicodramática. Paidós.

Castro, A., Vidal, G. P., da Silveira, B. D. S., \& de Oliveira, D. C. (2020). The survival through online Sociodrama: COVID-19, what do you want to tell me? Revista Brasileira de Psicodrama, 28(3), 176-186. https://doi.org/10.15329/23180498.20209

Crepaldi, M. A., Schmidt, B., Noal, D. S., Bolze, S. D. A., \& Gabarra, L. M. (2020). Terminalidade, morte e luto na pandemia de COVID-19: Demandas psicológicas emergentes e implicações práticas. Estudos de Psicologia, 37, e200090. https://doi.org/10.1590/1982-0275202037e200090

Cukier, R. (1992). Psicodrama bipessoal. Ágora.

Do Bú, E., Alexandre, M., Bezerra, V., Sá-Serafim, R., \& Coutinho, M. (2020, 18 de maio). Representações e Ancoragens Sociais do Novo Covid-19 e do Tratamento da COVID-19 por Brasileiros. Estudos de Psicologia, 37, e200073. https://doi. org/10.1590/1982-0275202037e200073

Fonseca, J. (2010). Psicoterapia da relação. Ágora.

Guimarães, L. A. (2020). Imagodrama: Uso de bonecos e objetos-auxiliares em psicodrama individual e on-line. Revista Brasileira de Psicodrama, 28(2), 106-117. https://doi.org/10.15329/2318-0498.20039

Salim Khouri, G. (2020). Internal psychodrama in the treatment of trauma: Handling drivers. Revista Brasileira de Psicodrama, 26(1), 51-65. https://doi.org/10.15329/2318-0498.20180012

Miguel, F. K. (2015). Psicologia das emoções: Uma proposta integrativa para compreender a expressão emocional. PsicoUSF, 20(1), 153-162. https://doi.org/10.1590/1413-82712015200114

Moreno, J. L. (1974). Psicoterapia de grupo e psicodrama. Mestre Jou.

Moreno, J. L. (1975). Psicodrama. Cultrix.

Moreno, J. L., \& Enneis J. M. (1984). Hipnodrama e psicodrama. Summus.

Moreno, Z. T. (1975). Psicodrama de crianças. Vozes.

Moreno, Z. T., Blonkvist, L. D., \& Rützel, T. (2001). A Realidade Suplementar e a Arte de Curar (E. A. N. do Vale, Trad.). Ágora.

Moreno, J. D. (2016). Impromptu Man:J. L. Moreno e as origens do psicodrama, da cultura do encontro e das redes sociais. Febrap. 
Organização Mundial da Saúde. (2020). Rueda de prensa semanal sobre la situación de COVID-19 en la Región de las Américas. https://www.paho.org/es/medios/rueda-prensa-semanal-sobre-situacion-covid-19-region-americas

Perazzo, S. (2010). Psicodrama: O forro e o avesso. Ágora.

Resolução CFP n. 11 (2018). Regulamenta a prestação de serviços psicológicos realizados por meios de tecnologias da informação e da comunicação e revoga a Resolução CFP n. 11/2012. Conselho Federal de Psicologia. https://atosoficiais. com.br/lei/orientacao-psicologica-pela-internet-cfp?origin=instituicao

Santos, A. J., \& Conceição, M. I. G. (2014). Espiral psicodramático: Ciência e arte do aquecimento. Revista Brasileira de Psicodrama, 22(1), 54-64.

Soliani, M. L. C. (2020) Realização Simbólica e realidade suplementar. In R. F. Monteiro (Org.), Técnicas fundamentais do psicodrama. Summus.

Vieira, F.M., Vieira, A. S., Fernandes, G.J. R. C., \& Reichow, J. R. C. (2018). A respiração como ferramenta de intervenção da psicoterapia corporal. In J. H. Volpi, \& S. M. Volpi, Psicologia Corporal. Centro Reichiano.

Vidal, G. P., \& Cardoso, A. S. (2020). Dramatização on-line: Psicoterapia da relação e psicodrama interno no psicodrama contemporâneo. Revista Brasileira de Psicodrama, 28(2), 131-141. https://doi.org/10.15329/2318-0498.20383

Vidal, G. P., \& Castro, A. (2020). COVID-19 e o luto de papéis: O encontro com o papel de sobrevivente. In C. D. Tomasi, J. Soratto, \& L. B. Ceretta (Orgs.), Interfaces da COVID-19: Impressóes multifacetadas do periodo de pandemia (pp. 30-31). UNESC. http://doi.org/10.18616/intcov07

\footnotetext{
7. O aquecimento específico, strictu sensu se refere à preparação da cena, cenário e aqui estamos fazendo um correlato entre as etapas existentes na prática psicodramática e os momentos da entrevista. Utilizamos construir o percurso de uma entrevista, ou mesmo as fases de um projeto — como se observa nos subtítulos deste artigo, em analogia às etapas de uma sessão socionômica.
} 